\title{
HOW THE INTERNAL STAKEHOLDERS PERCEIVE THE IMPLEMENTATION OF CONTROLLING
}

\author{
Mariana Sedliacikova ${ }^{1, a,{ }^{*}}$, Maria Moresova ${ }^{1,2, b}$, Milos Bikar $^{3, \mathrm{c}}$ and Dana \\ Bencikova $^{4, d}$ \\ ${ }^{1}$ Department of Business Economics, Faculty of Wood Sciences and Technology, Technical \\ University in Zvolen, T. G. Masaryka 24, Zvolen 960 53, Slovakia \\ ${ }^{2}$ Department of Corporate Economics and Management, Faculty of Economics, Matej Bel University \\ in Banská Bystrica, Tajovského 10, Banská Bystrica 975 90, Slovakia \\ ${ }^{3}$ Department of Corporate Finance, Faculty of Business Management University of Economics in \\ Bratislava, Dolnozemská cesta 1, 85235 Bratislava, Slovak Republic \\ ${ }^{4}$ Department of Corporate Economics and Management, Faculty of Economics, Matej Bel University \\ in Banská Bystrica, Tajovského 10, Banská Bystrica 975 90, Slovakia \\ asedliacikova@tuzvo.sk, ${ }^{b}$ mmaria.moresova@gmail.com, ${ }^{\mathrm{c}}$ milos.bikar@euba.sk, \\ ddana.bencikova@umb.sk \\ *Corresponding author
}

Cite as: Sedliacikova, M., Moresova, M., Bikar, M., Bencikova, D. (2017). How the internal stakeholders perceive the implementation of controlling, Ekonomicko-manazerske spektrum, 11(2), 32-44.

Available at: dx.doi.org/10.26552/ems.2017.2.32-44

\begin{abstract}
Controlling is considered to be one of the key tools that help to make the management of an enterprise more efficient, and thus adjust to continual changes of the economic environment of the present times. By implementing controlling into an enterprise, it becomes its inevitable part which helps coordinate all systems in the enterprise. It is all internal stakeholders who encounter controlling, i.e. the owners, managers, and the employees. However, for controlling to be efficient in an enterprise, it is essential to implement it appropriately, promote and enforce it, and gradually build it up, in order to achieve its most appropriate form. Psychological aspects help to understand how implementation of controlling is perceived by the employees, managers, and the owners. The main objective of this paper is to determine the effect of controlling from the psychological point of view, and from the view of the internal stakeholders. Using the data obtained in a survey, the paper also aims at proposing a model of implementing, enforcing, and using controlling in an enterprise. Within the empirical research, the authors have used a questionnaire as a method of surveying the given problem in the practice of Slovak enterprises. The results of the research enabled identification of the main barriers of implementing, enforcing, and using this tool in enterprises, as perceived by the employees, managers, and the owners. Based on the results, a standardized model of implementing, enforcing, and using controlling in Slovak enterprises has been proposed. This model will help to ensure the acceptance of controlling by all stakeholders, eliminate barriers to its implementation and enforcement in an enterprise, help understand its benefits by internal stakeholders, and enable an effective use and functioning of this tool.
\end{abstract}

Keywords: controlling, psychological aspects, internal stakeholders

JEL Classification: M12, M21, M29 


\section{Introduction}

Horvath (2003), defines controlling as a function which helps to improve coordination between planning, management, and the information flow in an enterprise. Controlling is currently considered to be one of the most important supportive tools in managing an enterprise. In Slovakia, as stated by Eschenbach (2004), and Bikar and Kmetko (2015), enterprises of all sizes and specializations are becoming more and more aware of controlling and begin to apply it in their operations. According to studies by Uradnicek and Zimkova (2009), Sedliacikova et al. (2015), Satanova et al. (2015), Hajduchova et al. (2016), McAdam et al. (2016), and Sedliacikova et al. (2016), in some enterprises, controlling is partially implemented without the management realizing it. In micro and small enterprises, where a simple corporate transformation process is applied, with participation of only few employees and simple technology, the role of a controller is often assumed by the owner or the managing director. As emphasized by Jung (2014), controlling is not used as a short-term problem solution, but at the same time it serves as a managerial tool which should be fully and permanently integrated into the enterprise. According to Ambrosini et al. (2009), Becker (2009), and Gadatsch (2009), the philosophy of controlling, within the frame of general orientation of value-creating models, can only be present implicitly, in the form of basic corporate strategies. On the basis of these, the corporate goals are determined as the next step. In controlling, as noted by Waniczek (2002), psychological components play an important role. There exist six psychological rules between the controller and line managers, or employees, who accept the controller's advice and services, which should be applied in an appropriate manner in order to achieve effective controlling. The content of the individual rules is mutually complemented. The first psychological rule of controlling is motivation. An enterprise can greatly affect motivation of its employees through its activities. As mentioned by Lumpkin et al. (1996), Oliveira et al. (2015), and McIvor (2016), it is not possible to only apply one single method of motivation for all employees. In motivation, it is essential to ensure for the controller to be perceived in a positive way by the employees, i.e. as a helper rather than a guard. Feedback, as the next psychological rule, does not only comprise verbal or non-verbal information, but, according to Andreas (2004) and Le Flanchec et al. (2017), also the working climate, expectations, and corporate culture. The expectations are an important psychological 'lever', since both the positive and the negative ones reflect in employee performance. It has been scientifically proved that expectations attract success, which means that employees who are approached with more trust are more successful than those who we are skeptical towards. This is known as the Pygmalion effect. Exchange of feedback between the controller and the addressee is enabled through effective communication, which is the next psychological rule. With regard to controlling, for communication to be most effective, it is essential, as stated by Willcocks and Sykes (2000), that each employee make their own decisions regarding communication with supervisors, i.e. who the employee may speak to and what about should not be mandated. Another factor is creating trust. Trust, as mentioned in Le Flanchec et al. (2017), is one of the basic pillars of a successful enterprise. Corporate culture that lacks trust may be harmful not only to the interpersonal relations, but may also reflect in the productivity of the employees. This disrupts the process of fulfilling the corporate goals as well as the overall results of the organization. According to Hudson et al. (2001), Riemenschneider et al. (2003), and Osorio (2017), the objectives can be enforced through exerting pressure on the employees, or through a method which results from personal behavior of individual people. People respond to pressure which is put on them in different ways. Change is the last psychological rule in the process of implementing and building controlling in an enterprise. Soulsby and Clark (1998), Waniczek (2002), and Eschenbach and Siller (2012) state that employees respond to change differently. Change may be latently perceived as a threat. 
Introducing change to employees must be facilitated in a way which enables them to feel involved, and to acknowledge the need to participate in change implementation. From the above mentioned it may be concluded that controlling cannot function without the coordination between the controller and the managers, which has been agreed upon by Carroll et al. (1987), Secundo and Elia (2014), and Feldbauer-Durstmuller and Hiebl (2015). Grant (2016), however states that correctly functioning controlling also requires an effective activity of the employees. Controlling in an enterprise may only be highly efficient if all internal stakeholders have encompassed and understood its concept. It is for this reason that psychological aspects of perceiving controlling are its inevitable part. In case the enterprise pays sufficient attention to psychological aspects of controlling from the point of view of all its internal stakeholders, the implementation and use of controlling in this enterprise should be flawless and respected by all employees and internal stakeholders that exist in the particular enterprise. Based on the above statements, research into how the implementation of controlling is perceived by the individual internal stakeholders appears to be very relevant, and this field rather unexplored. Therefore, the main objective of this paper is to determine the effects of controlling from the psychological point of view and from the view of the internal stakeholders, through the data obtained in an empirical research. At the same time, the paper focuses on proposing a model of implementing, enforcing, and using controlling in an enterprise.

\section{Methodology}

Methodology of the paper consists of four phases. Within the first phase, the authors performed a detailed review of literary resources related to the topic. Setting theoretical basis for the research was important for the proposal of the frame model. In this phase, scientific methods of summarization, knowledge synthesis, analogy, and deduction were used. The second phase focused on the analysis of the primary resources obtained from the empirical research by the questioning method. The questionnaire aimed at determining such psychological factors in the practice of Slovak enterprises which have a direct influence on perceiving benefits and barriers of controlling by the individual internal stakeholders in the phase of implementing, enforcing, and using controlling in business practice. The data obtained in the questionnaire survey were evaluated by the description, numerical, and graphic methods. In the third phase, a frame model of implementing, enforcing, and using controlling in enterprises was proposed. Introducing this model to business practice will result in controlling being accepted by all internal stakeholders. This means eliminating all barriers of its implementation and enforcement, understanding its benefits, and ensuring its effective functioning in an enterprise. The frame model could be proposed thanks to the use of a systemic approach. In the final phase, the methods of analogy, deduction, and summarization of the knowledge enabled the authors to define the theoretical and practical contributions of the conducted research.

\subsection{Data collection and the research sample}

The conducted empirical research served as a foundation to acquiring knowledge related to psychological factors affecting the implementation of controlling with regard to the internal stakeholders. According to the data by the Statistical Office, in the time of research, there were 565,869 enterprises registered in the Slovak Republic. The size of the research sample was determined on the basis of the statistical approach, which can be considered most accurate. This way, the minimum number of respondents (enterprises) that allowed generalization of the results was set to 400 . The questionnaire was distributed among 4,935 subjects, and 412 
respondents have participated in the research, which represents a return rate of $8.35 \%$. The electronic questionnaire was sent to employees, managers, and owners of all types of enterprises (micro, small, medium, and large). The questions were specially designed to enable authors to find out what the real situation related to the problem in the Slovak Republic is. The questionnaire was divided into four parts, as stated below:

- Part A-4 questions: basic characteristics of the enterprise (A1-A4),

- Part B - 4 questions: implementation and enforcement of controlling (B5-B8),

- Part C - 4 questions: benefits and barriers of controlling (C9-C12),

- Part D - 2 questions: psychological aspects (D13-D14).

Questions in Part A focused on the size of an enterprise (micro, small, medium, and large enterprises), business purpose (production, non-production, and other enterprises), length of enterprise's existence in the market, legal form of business, and the position of the respondent in the enterprise. Question in Part B aimed at finding out the respondents' opinions about what should precede the implementation of controlling in the enterprise, how controlling should be implemented, and the factors that are inevitable to implement it. Questions in Part C dealt with the problems of financial and non-financial benefits of controlling, and barriers of its implementation and enforcement in the enterprise. In the last part, which used the Likert scale, respondents expressed what effect controlling has on chosen aspects. In the last questions, respondents were asked to express their feelings related to implementing and building controlling in their enterprise.

\section{Results}

\subsection{Results of the empirical research}

The next part presents the results of the questionnaire research, which investigated the effect of psychological factors on the internal stakeholders with regard to the implementation of controlling. The research sample is formed by micro, small, medium, and large enterprises, which operate in the Slovak Republic. Of the total number of addressed respondents, microenterprises represent $24 \%$, of which $16 \%$ are production and $84 \%$ are non-production oriented enterprises. In the group of micro-enterprises, $42 \%$ have been operating in the market for more than 15 years, $40 \%$ less than 15 years, and the remaining percentage of enterprises have been in the market for less than 5 years. As to the legal form of business, $62 \%$ of micro-enterprises are businesses with limited liability, 30\% are sole traders, $6 \%$ freelancers, and the other respondents stated a different form of business. With regard to the working position in the micro-enterprises, the research sample was represented as follows: 55\% owners, $17 \%$ managers, and $28 \%$ employees. Small enterprises have a $19 \%$ representation in the research, of which number $45 \%$ are production, and $55 \%$ non-production oriented enterprises. As many as $45 \%$ of small enterprises have been operating in the Slovak market for more than 15 years, $36 \%$ more than 5 and less than 15, and the remaining percentage of enterprises have been in the market for less than 5 years. Legal form of business is represented among small enterprises as follows: the largest representation (79\%) is formed by enterprises with limited liability, joinedstock companies hold $16 \%$, and cooperative as a legal form was mentioned by $2.6 \%$ enterprises. Other enterprises have indicated a different legal form of business. As to the working position, in small enterprises, $25 \%$ of the respondents are owners, $39 \%$ are managers, and the remaining $35 \%$ are employees. Medium enterprises represent $29 \%$ of the total number of respondents, of which 52\% rank among production, and 48\% non-production enterprises. Almost $71 \%$ of medium enterprises have been operating in the market for more than 15 years, other enterprises 
have been in the market for more than 5 years. With regard to the legal form of business, more than $37 \%$ of enterprises are joint-stock companies, while more than a half of this group are limited liability enterprises (53\%); and finally, the state-owned enterprise was indicated by $3.3 \%$ of respondents. Among medium enterprises, over a half of respondents were employees (58\%), $37 \%$ were managers, and only $5 \%$ were owners. The category of large enterprises was formed by $28 \%$ of the total number of respondents, of which $50.4 \%$ were production, and the rest were non-production oriented enterprises. More than $74 \%$ of large enterprises that participated in the research have been in the market for more than 15 years. Over 5 years was indicated by $16 \%$, and the remaining enterprises have been operating in the market for less than 5 years. Almost $62 \%$ of respondents are joint-stock companies, $29 \%$ are private limited businesses, and 5\% are state-owned. As to the working position, $70 \%$ of respondents from large enterprises are employees, $29 \%$ are managers, and only $1 \%$ of the sample is represented by the owners. Within the following phase of the empirical research, the most appropriate way of implementing controlling in an enterprise was proposed (Figure 1). The main purpose of question B1 was to find out which activities should precede the implementation of controlling in the enterprise. The most significance $88 \%$ was given to the analysis of working tasks and familiarizing the employees with the subject before implementing controlling in the enterprise. The analysis of organization structure and employee training were indicated by $84 \%$ of respondents. The analysis of hiring an external expert in the field of controlling appears to be of least importance, as $42 \%$ consider it unnecessary.

Figure 1: Activities preceding the implementation of controlling

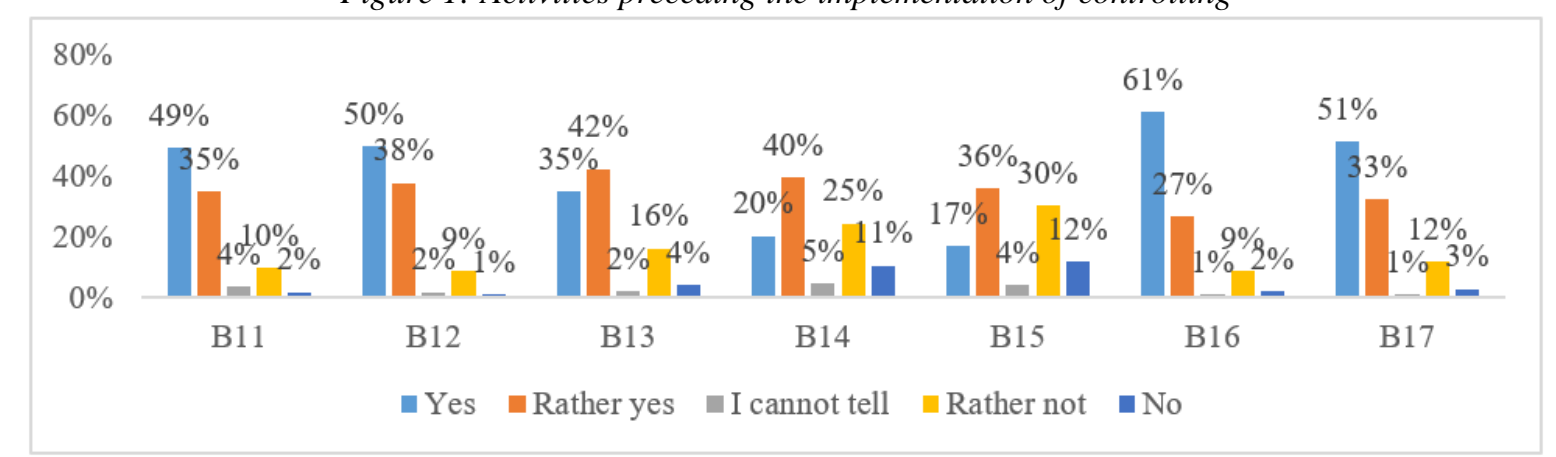

Source: Authors

Authors' note: B11 - analysis of organization structure; B12 - analysis of work tasks; B13 - analysis of working skills; $B 14$ - analysis of market in order to hire an expert; $B 15$ - analysis of possibilities to hire and external expert; B16-familiarizing employees with the subject; B17 - training

The following question focused on the most appropriate way of implementing controlling in the enterprise. The responses were rather varied, and based on them, it is not possible to determine a specific way of implementation as the best one. Implementing controlling gradually was suggested as a response by $33 \%, 34 \%$ would prefer to do it in phases. The next question dealt with the effect of six psychological rules on implementing and enforcing controlling in an enterprise (Figure 2). All suggested psychological rules appear to be of high or very high importance, according to the research. All factors were marked with more than $75 \%$ of importance, while communication and feedback are the most important factors. Based on the research results, it can be stated that all mentioned rules are highly important in implementing and enforcing controlling, and the management of the enterprise should not neglect any of them. 
Figure 2: The effect of six psychological rules

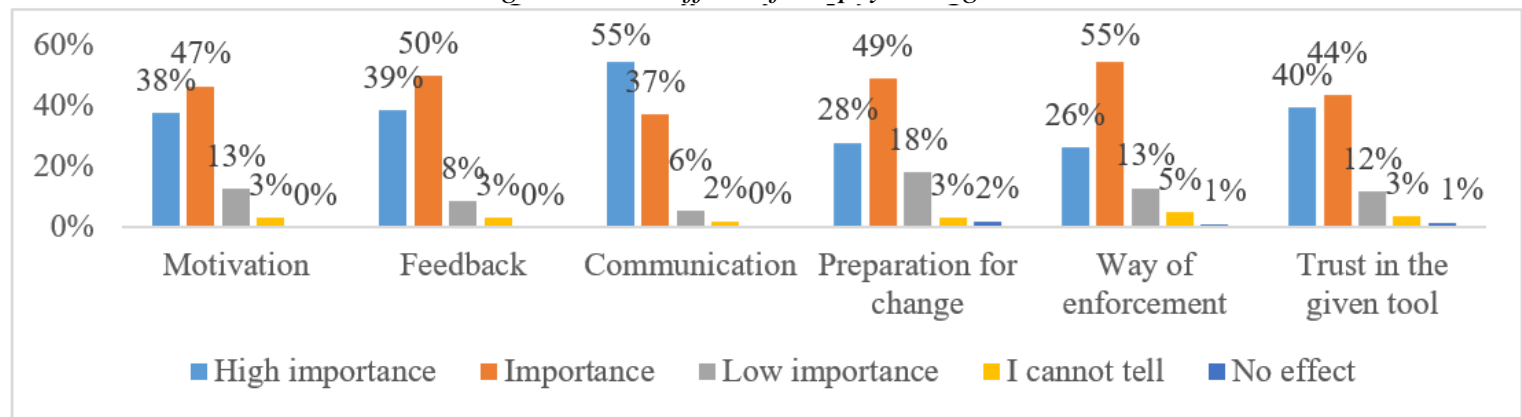

Source: Authors

The last question in the second part focused on activities that respondents consider essential for the implementation of controlling to be efficient. Almost half of the respondents (48\%) indicated the style of managing which uses initiative and suggestions of middle management in making important operational decisions as inevitable for efficient implementation of controlling. An inseparable part of successful implementation also appears to be reorganizing the planning-controlling and motivational systems in the enterprise, as well as developing an internal information system. A significant portion of respondents thinks it is necessary to change the corporate culture. On the other hand, change in organization structure, decentralizing the management process respectively, does not play an important role in implementing controlling. Based on the results, it may be concluded that the factors that determine an effective implementation of controlling in an enterprise are: inevitable cooperation with middle management, and economically designed internal information system, as well as the system of planning and control. It is necessary to focus on adjusting the corporate culture and reorganizing the motivation system, while paying attention to appropriate way of communication. Next, attention was paid to financial and non-financial benefits of implementing controlling into an enterprise (Figures 3 and 4). The most frequently indicated financial benefits were the following: growth in the economic outcomes, more accurate fulfillment of financial plans, growth in enterprise profitability, and the overall increase in the value of an enterprise (mainly from the view of employees). Among the most significant nonfinancial benefits are: improvement of the performed processes with the effect on reducing costs, increasing the efficiency of quality of processes, clearer information and better control of achieving goals, aligning plans in accordance with the goals, and the possibility to detect deviations.

Figure 3: Financial benefits of implementing controlling into an enterprise

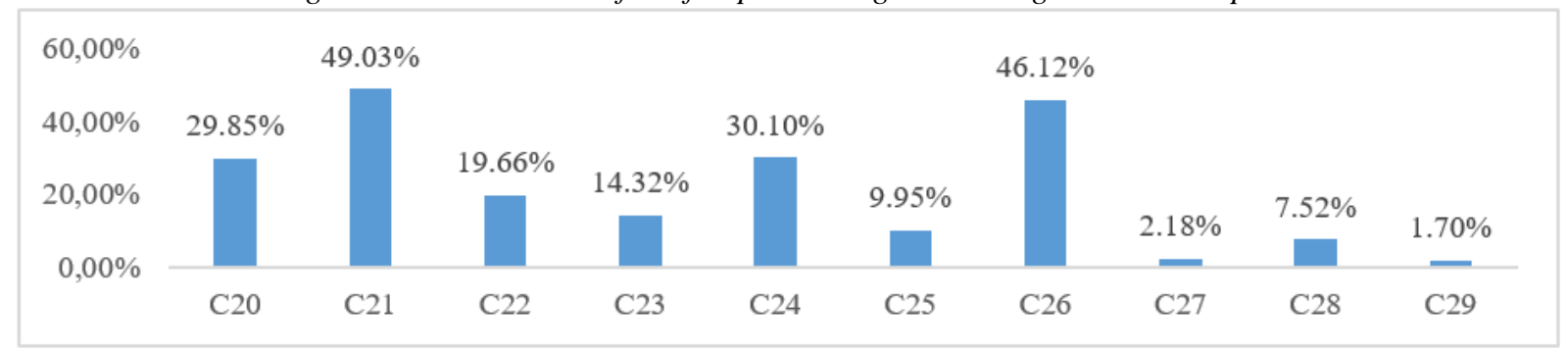

Source: Authors

Authors' note: C2O - increased value of the enterprise; C21-growth in the economics outcomes; C22 - growth in cash flows; C23 - growth of the average wage in the enterprise; C24 - growth in enterprise profitability; C25 - growth in enterprise liquidity; C26 - More accurate financial plans and their fulfillment; C27 - no benefit; C28-don't know; C29-other; 
Figure 4: Non-financial benefits of implementing controlling into an enterprise

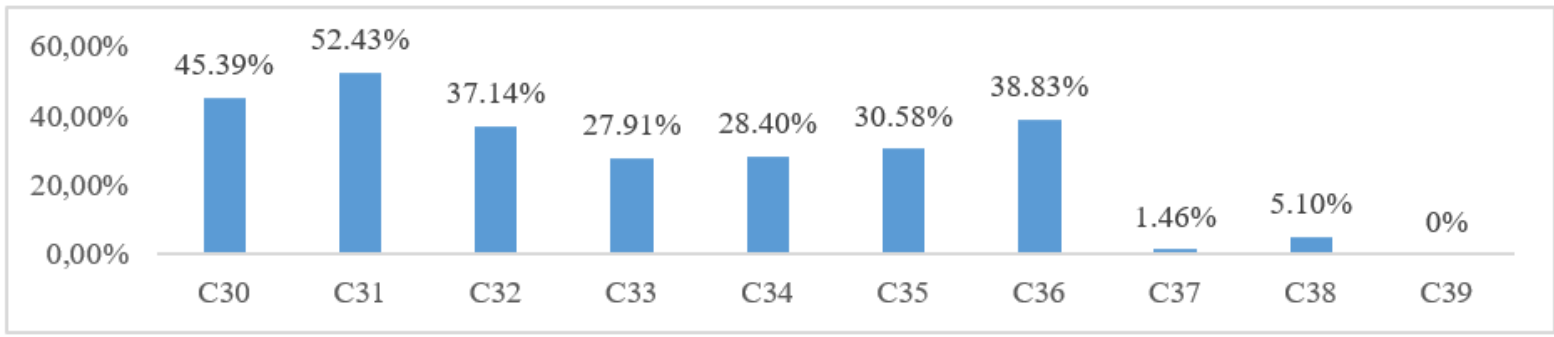

Source: Authors

Authors' note: C30 - Clarification of information related to optimal managerial decisions; C31 - Improvement of process performance in order to reduce costs; C32 - Control of achieving corporate goals and goals at lower levels of management; C33 - Alignment of all kinds of plans in accordance with the goal (required condition); C34 - Possibility to detect deviations through measurable indicators; C35 - Increase in work productivity; C36 Increasing the efficiency of quality of processes; C37 - no benefit; C38 - I cannot tell; C39 - Other;

The next question, which focused on barriers of implementing and enforcing controlling in an enterprise, aiming at the internal stakeholders, was specifically adjusted for managers, owners, and employees. Among the most frequently indicated concerns of employees belong the following: a worry that they will be extensively controlled and under a constant scrutiny, which relates to another fear of not fulfilling the norms. Employees are also concerned about impaired relationships in the workplace. More than $41 \%$ of employees have no concerns (53 $\%$ of them being employees of those enterprises which have already implemented controlling into their operations). The enterprise owners express concerns with implementing and enforcing controlling in relation to the given tool not being accepted by employees. They worry that employees may sabotage the tool or there may be conflicts between the manager and the controller. As investors of their own financial resources into the enterprise, the owners are also worried that the financial resources spent on the implementation of controlling will be worthless, or the effect of implementation will be lower than the resources used to develop it. Among the most frequently indicated concerns of managers belong: a worry of the given tool not being respected by the employees, or being sabotage, and the fear of potential conflicts between managers and the controller. Even managers themselves expressed concerns as to the excessive control from the top management. On the other hand, however, $35 \%$ of managers express no concerns or worries. These are mainly managers in those enterprises where controlling has already been implemented, or it planned to be implemented in a short time. The following question aimed to find out how strong the effect of psychological aspects in implementing controlling is. The responses were segmented according to the individual groups of stakeholders in order to better define the effect of each psychological aspect. In implementing controlling, the employees view positively mainly the following aspects: relevance of information, improvement in evaluating their performance, motivation, and communication in the workplace. On the other hand, what is viewed negatively is the pressure in the workplace, and the increase requirements related to employee workload. The number of work positions, or promotion, are not affected by implementation of controlling, as stated by majority of respondents in this group. The owners view the efficient use of working time, improvement in evaluating employee performance, relevance of information, and motivation as the most significant and positive factors of implementing controlling. Similar to the previous group, owners also consider the pressure in the workplace to be a negative contribution of controlling (it is mostly owners of those enterprises where controlling has not yet been implemented). Managers view similar factors of implementing controlling as positive: improvement in evaluating employee performance, relevance of information, and motivation of employees. Another positive factor of controlling, as perceived by managers, is the increase in customer 
satisfaction, while the only negative factor according to this group is the pressure in the workplace. The most significant responses are shown in Figure 5.

Figure 5: Which factors affect the implementation of controlling into an enterprise?

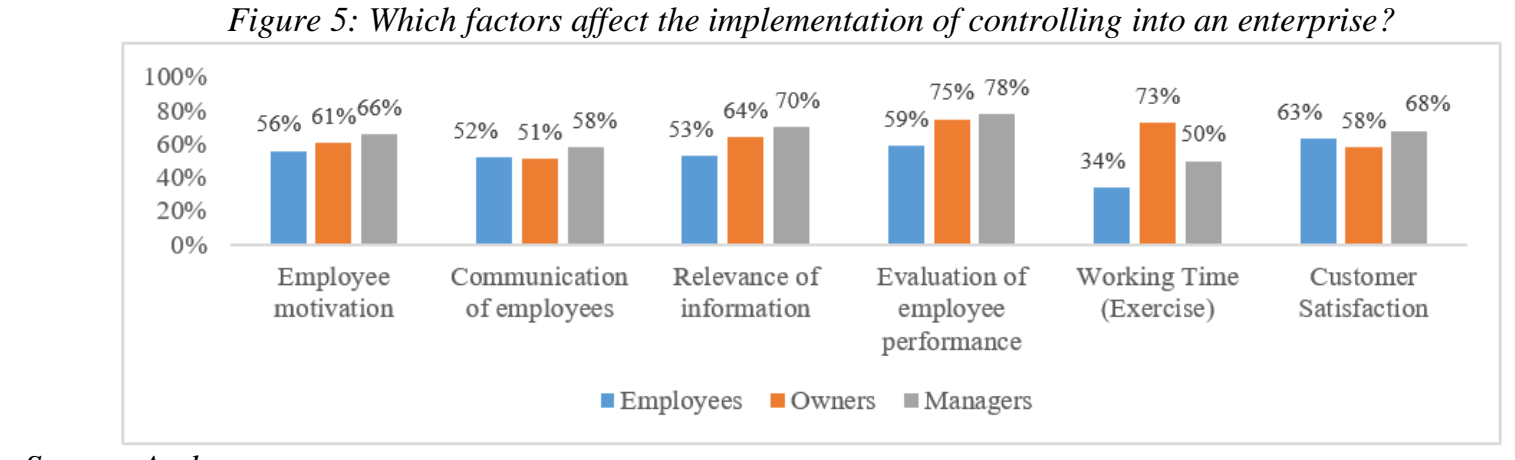

Source: Authors

The last question of the survey focused on the feelings evoked among individual respondents by building a controlling system in their enterprise. Among the most frequent positive feelings are curiosity, motivation, and satisfaction. The most significant negative feelings, as viewed by the internal stakeholders, are uncertainty (in $52 \%$ of enterprises which have not implemented controlling in their operations), lack of interest, and fear.

\subsection{Model of implementation of controlling}

Implementation of controlling is a long-term process. Therefore, as noted by Riemenschneider et al. (2003), and Andreas (2004), it is appropriate that the process of implementation be divided into several subsequent phases, which may be specifically adjusted according to the needs of each individual enterprise. The first phase is pre-implementation. Already in this phase, it is necessary to initiate preparation of employees for the change, and gradually build their trust in this tool. According to Becker et al. (2009), Chebukina et al. (2013), and Le Flanchec et al. (2017), the implementation itself, analyzing the current situation, should be preceded by the analysis of working tasks, organization structure, and the analysis of the field the specialist for controlling operates in, which has also been confirmed by the research results. Figure 6 presents the activities of the pre-implementation phase, where the basis for the development was represented by the results of the empirical research, as well as the theoretical foundations.

Figure 6: Activities in the pre-implementation phase

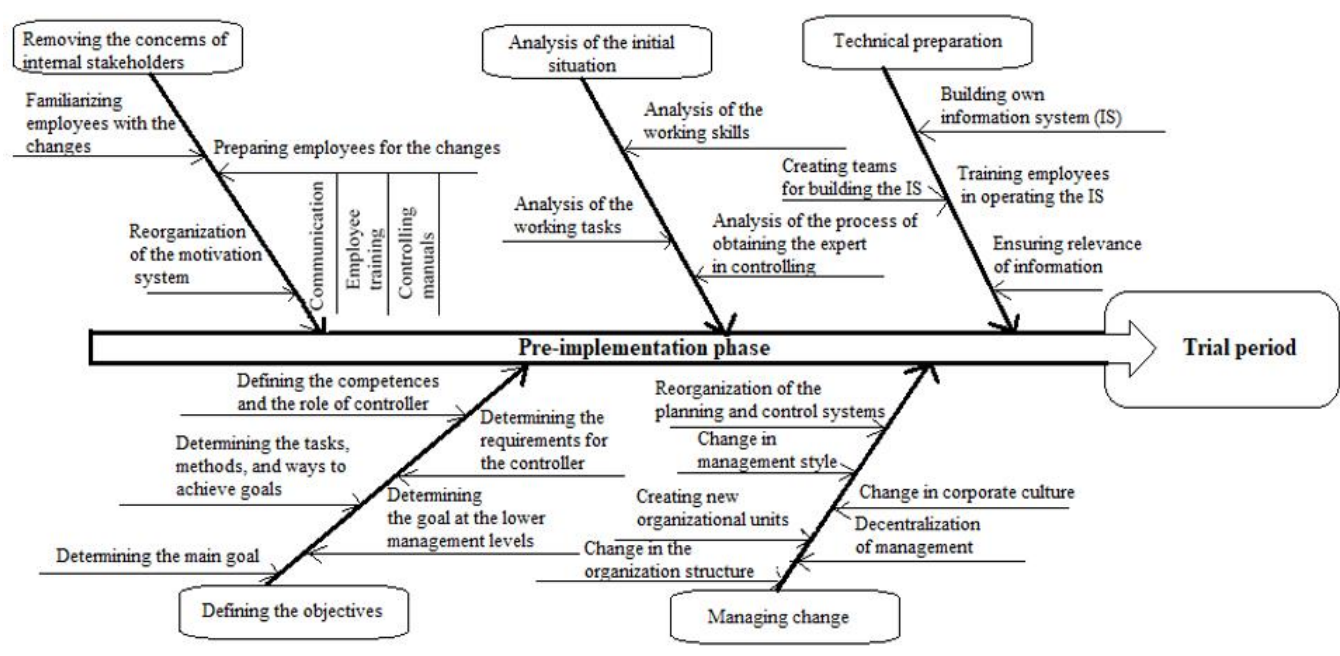

Source: Authors 
The authors have also included a trial period into the proposed model. This phase includes all the previously performed steps. As agreed on by Waniczek (2002) and Eschenbach et al. (2012), by means of an appropriate combination of psychological rules, it is possible to eliminate the barriers, and effectively implement controlling into an enterprise. The main goal of the trial period is to make all the necessary corrections in such way that prevents potential problems, and tests the efficiency of controlling. Figure 7 presents the concerns related to the trial period, and the psychological rules used to remove them, which must be adhered to in order to achieve efficiency of the trial period. As soon as the barriers in building controlling have been removed, and this tool begins to satisfy the needs of the management and the executives, the implementation phase can start. The implementation phase should bring the first results in the enterprise. The achieved goals are monitored, fulfilling plans is controlled, and the deviations are compared. In this phase, as presented by Andreas (2004), the unpredictable events or problems that may have occurred are fine-tuned, corrected, and solved, and the exchange of information between departments is harmonized and synchronized. The postimplementation phase in the use of controlling must, however, not be forgotten. Even though the process of implementation is in fact completed at this point, it does not mean that controlling in the enterprise will remain in this 'implementation stage' for a longer period of time. Constant development and adjustment to changes in the business environment is essential for an enterprise, while this also relates to controlling. In the end of this part, the authors are presenting a time and material schedule of implementing controlling in an enterprise, as shown in Figure 8 . The given model presents five phases, from the pre-implementation phase, to the phase after the actual implementation and use of controlling, where the innovative function of controlling manifests in its full capacity. The model was proposed in such way that enables specific modifications for particular enterprises and can be used in different fields of business. The schedule is proposed for the period of one year, in the end of which the effectively implemented system of controlling may be greatly beneficial for the enterprise. The innovation phase of the system is implemented according to the needs of the particular enterprise, with regard to the changes in the business environment.

Figure 7: Trial period-concerns and rules how to deal with them

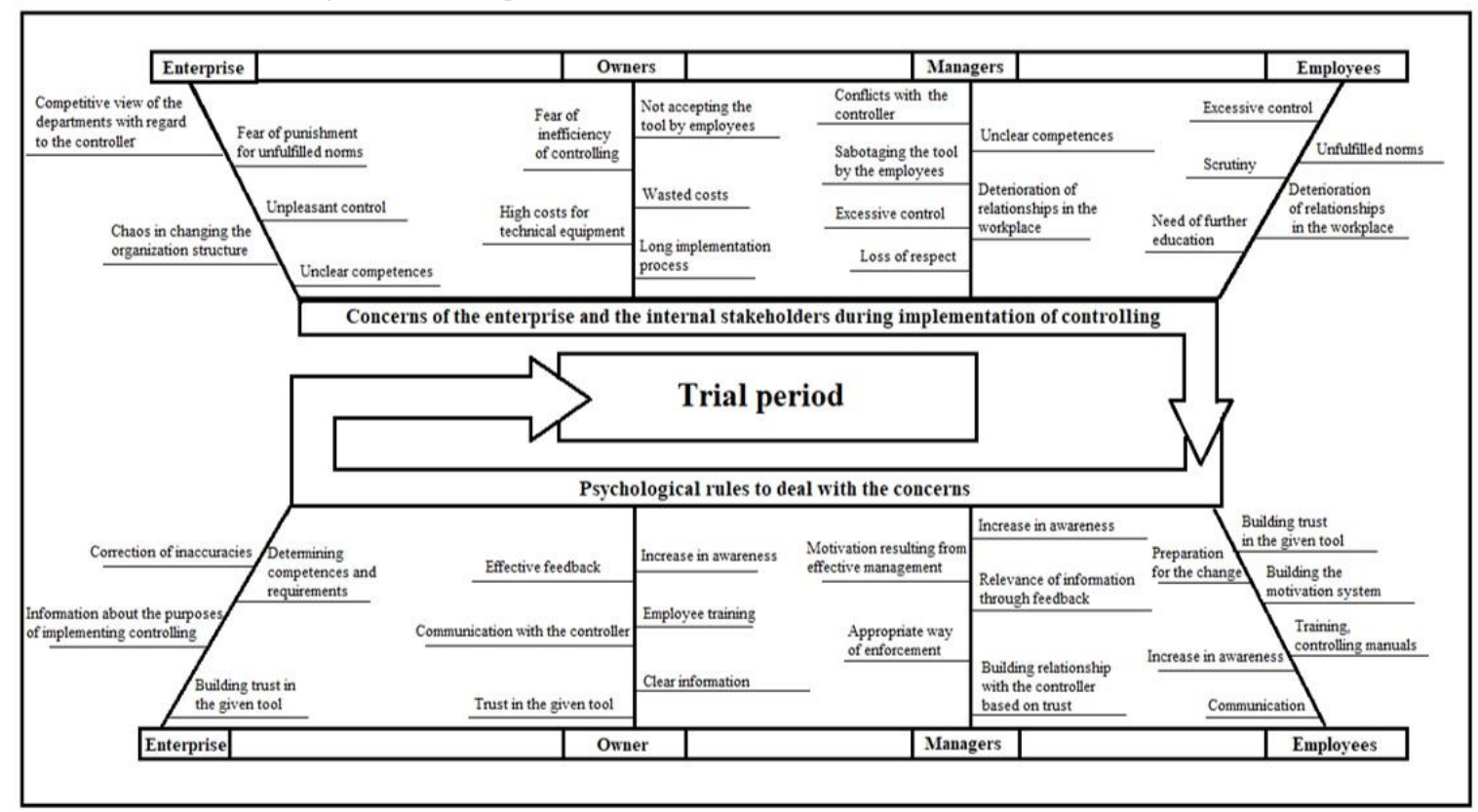

Source: Authors 


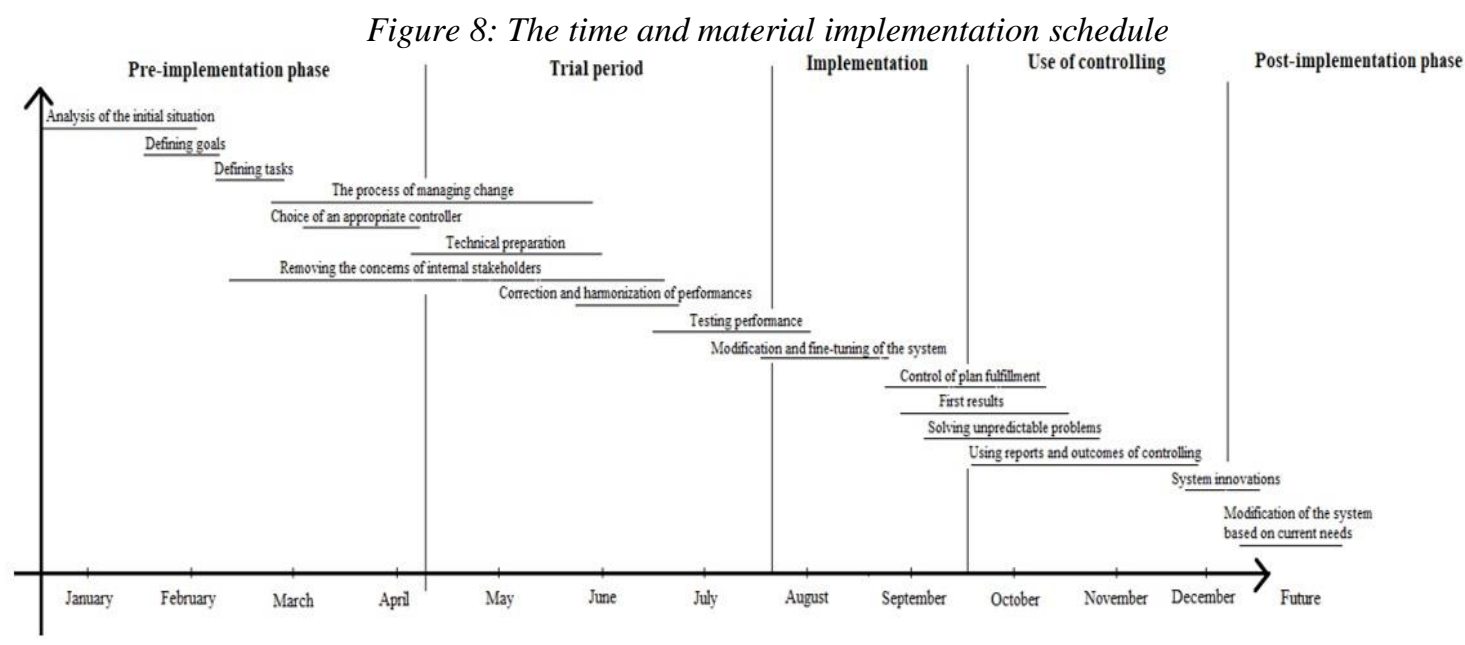

Source: Authors

\section{Discussion}

The following conclusions were drawn from the questionnaire survey: The research sample was composed of all size categories of enterprises operating in Slovakia, with micro-enterprises accounting for $24 \%$ of all enterprises surveyed, small enterprises representing $19 \%$, medium $29 \%$, and large enterprises $28 \%$. At the same time, the representation of all internal stakeholders, i.e. employees, owners and managers, was examined. It is familiarizing the employees with the planned changes, as well as their training that should precede the introduction of controlling into the enterprise. With regard to the analysis of the initial situation, it is mainly the analysis of the organizational structure, working tasks and skills, which has also been noted by Andreas (2004) and Rautenstrauch and Muller (2005). The research further indicated that communication has a great impact on the implementation, from which the other aspects, such as motivation, feedback, preparation for change, enforcement, and trust in controlling are developed, as pointed out by Waniczek (2002), Garengo (2009), and Eschenbach and Siller (2012), and management should not neglect any of these aspects. The third part of the survey was devoted to financial and non-financial benefits and barriers to the introduction of controlling. As presented by Collis and Jarvis (2002) and La Flanchec et al. (2017), barriers are the most common reason why controlling is not introduced into enterprises. The main focus while analyzing the data was put on the internal stakeholders. Employees, who accounted for $50 \%$ of respondents, feel the most frequent fears of introducing controlling from excessive control, unfulfilled norms, and deterioration of workplace relationships. Managers as the operating authority are afraid of the given tool not being accepted by employees, of conflicts between them and the controller, and the excessive control of their activities, which was also agreed on by Bradley (2008) and Laud et al. (2016). Owners of the company are particularly concerned about the spent financial resources, and fear that the implementation does not produce the desired effect but rather produces workplace conflicts and sabotage of the tool by employees, as claimed in Willcocks and Sykes (2000). The most frequently indicated benefits of controlling from the financial point of view are the economic growth, the increase in value of the enterprise, and growth of profitability, or more precisely, the fulfillment of the financial plans, as it was stated by the all internal stakeholders. The most common non-financial benefits are improving the performance of processes while reducing costs, and enabling a clear flow of information, as well as more efficient quality of processes. Similar non-financial benefits of controlling were also presented by Chebukina et al. (2013). The last part of the questionnaire 
survey, focused on psychological aspects, shows that for all stakeholders, controlling has the most positive impact on the relevance of information, customer satisfaction, and the improvement of employee performance, while the most negative effect of controlling is creating pressure in the workplace, and higher workload. The most common feelings resulting from implementing and building controlling are: curiosity, motivation, and satisfaction. Based on this reason, the top management of the enterprise and the controller should try to provide the employees with the most relevant information about controlling and to reorganize the incentive system in order for the employees to remain motivated and willing to cooperate.

The presented model is composed of five phases, while each phase consists of several steps. In the pre-implementation phase, as emphasized by Andreas (2004) and Chebukina et al. (2013), it is essential to analyze the initial situation and to determine goals. The trial period, which is included in the proposed model, should mainly help to remove the discovered drawbacks and examine the functioning of controlling in an enterprise, as confirmed by Jung (2014). Eschenbach and Siller (2012) suggests that for each enterprise, different way of implementing controlling is suitable. It is only after controlling has been implemented into the whole enterprise that the initial implementation process is completed. However, the postimplementation phase, as agreed on by Eschenbach (2004) and Gadatsch (2009), should not only serve the purpose of analyzing the efficiency of the implemented tool, but at the same time for adapting controlling to real conditions of business practice.

\section{Conclusion}

Controlling can be defined as a tool which helps to make such decisions that lead to fulfillment of the strategic goals; enables flexible response to changes, uses opportunities, and eliminates threats. In business practice, the fact that this tool affects the individual internal stakeholders in the enterprise, is often forgotten. Owners, managers, and mainly employees, are influenced by psychological aspects, which greatly influence the effectiveness and efficiency of controlling. The proposed model of implementation, enforcement and use of controlling, which emphasizes the respect for psychological aspects of perceiving controlling, is applicable for all types of enterprise and offers a platform for partial modifications of several steps into the specific conditions of each enterprise. The given problem is largely unexplored and provides space for deeper research and analysis. Further research in the given field should focus on different psychological aspects than the ones which are mentioned in this paper, should analyze the individual aspects in more detail, or, alternatively, find its application in other regions within the European Union.

\section{Acknowledgment}

This paper is an output of the scientific project VEGA No. 1/0010/17 and project APVV14-0506.

\section{References}

Ambrosini, V., Bowman, C. \& Coller, N. (2009). Dynamic capabilities: An exploration of how firms renew their resource base. British Journal of Management, 20(1), 9-24.

Andreas, I.N. (2004). Firm performance effects in relation to the implementation and use of enterprise resource planning systems. Journal of Information Systems, 18(2), 79-105.

Becker, W. \& Balzer, B. (2009). Controlling eine instrumentelle perspektive. Bamber, Germany: Otto Friedrich Universität Bamberg. 
Bikar, M. \& Kmetko, M. (2015). Global economy, monetary policies and their impact on financial markets. European financial systems 2015. Proceedings on the $12^{\text {th }}$ International Scientific Conference. Brno, Czech Republic, 37-44.

Bradley, J. (2008). Management based critical success factors in the implementation of enterprise resource planning systems. International Journal of Accounting Information Systems, 9(3), 175-200.

Carroll, S.J. \& Gillen, D.J. (1987). Are the classical management functions useful in describing managerial work? Academy of Management Review, 12(1), 38-51.

Chebukina, M.V. et al. (2013). Controlling as a tool for implementation of the system for the enterprise resource potential management in its capitalized form. World Applied Sciences Journal, 27(4), 444-447.

Collis, J. \& Jarvis, R. (2002). Financial information and the management of small private companies. Journal of Small Business and Enterprise Development, 9(2), 100-110.

Eschenbach, R. (2004). Controlling. $2^{\text {nd }}$ ed. Prague, Czech Republic: ASPI Publishing.

Eschenbach, R. \& Siller, H. (2012). Profesionální controlling. $2^{\text {nd }}$ ed. Prague, Czech Republic: Wolters Kluwer.

Feldbauer-Durstmuller, B. \& Hiebl, M.R.W. (2015). Aktuelle trends und entwicklungen im controlling in und für KMU: Eine einführung der gastherausgeber. ZfKE - Zeitschrift für KMU und Entrepreneurship, 63(3-4), 193302.

Gadatsch, A. (2009). IT-Controlling-Konzepte und aktuelle situation in der Praxis. Wirtschaftsinformatik, 51(3), 295-305.

Garengo, P. (2009). A performance measurement system for SMEs taking part in quality award programmes. Total Quality Management \& Business Excellence, 20(1), 91-105.

Grant, D. (2016). Business analysis techniques in business reengineering. Business Process Management Journal, 22(1), 75-88.

Hajduchova, I. et al. (2016). Slovakian forest-based sector in the context of globalization. BioResources, 11(2), 4808-4820.

Horvath, P. (2003). Controlling. $9^{\text {th }}$ ed. München, Germany: Verlag Valen.

Hudson, M. Smart, A. \& Bourne, M. (2001). Theory and practice in SME performance measurement system. International Journal of Operations \& Production Management, 21(8), 1096-1115.

Jung, H. (2014). Controlling. $4^{\text {th }}$ ed. München, Germany: De Gruyter Oldenbourg.

Laud, R., Arevalo, J. \& Johnson, M. (2016). The changing nature of managerial skills, mindsets and roles: Advancing theory and relevancy for contemporary managers. Journal of Management \& Organization, 22(4), 435-456.

Le Flanchec, A., Mullenbach-Servayre, A. \& Rojot, J. (2017). Human resource management and innovation strategies: A French study based on the response 2011 database. International Conference on Regulation, Change and the Work. Ottawa, Canada, 173-202.

Lumpkin, G.T. \& Dess, G.G. (1996). Clarifying the entrepreneurial orientation construct and linking it to performance. The Academy of Management Review, 21(1), 135-172.

McAdam, M., McAdam, R., Dunn, A. \& McCall, C. (2016). Regional horizontal networks within the SME agrifood setor: An innovation and social network perspective. Regional Studies, 50(8), 1316-1329.

McIvor, R. (2016). An analysis of the application of process improvement techniques in business process outsourcing. International Journal of Quality \& Reliability Management, 33(3), 321-343.

Oliveira, J., Filho, E.E., Nagano, M.S. \& Ferraudo, A.S. (2015). Managerial styles of small business owners; A study based on the organizational life cycle and on concepts concerning managers' functions and roles. Review of Business Management, 17(57), 1279-1299.

Osorio, A. (2017). Self-interest and equity concerns: A behavioral allocation rule for operational problems. European Journal of Operational Research, 261(1), 205-213.

Rautenstrauch, T. \& Muller, Ch. (2005). Verständnis und organisation des controllings in kleinen und mittleren unternehmen. Zeitschrift für Planung \& Unternehmenssteuerung, 16(2), 189-209.

Riemenschneider, C.K., Harrison, D.A. \& Mykytyn, P.P. (2003). Understanding it adoption decisions in small business: integrating current theories. Information \& Management, 40(4), 269-285.

Satanova, A. et al. (2015). How Slovak small and medium manufacturing enterprises maintain quality cost: An empirical study and proposal for a suitable model. Total Quality Management \& Business Excellence, 26(1112), 1146-1160.

Secundo, G. \& Elia, G. (2014). A performance measurement system for academic entrepreneurship: A case study. Measuring Business Excellence, 18(3), 23-27.

Sedliacikova, M. et al. (2016). Improving the performance of small and medium wood-processing enterprises. BioResources, 11(1), 439-450.

Sedliacikova, M., Vacek, V. \& Sopkova, E. (2015). How Slovak small and medium enterprises perceive financial controlling. $4^{\text {th }}$ World Conference on Business, Economics and Management. Ephesus, Turkey, 82-85. 
How do Internal Stakeholders Perceive the Implementation of Controlling Authors: Mariana Sedliacikova et al.

Soulsby, A. \& Clark, E. (1998). Controlling personnel: Management and motive in the transformation of the Czech enterprise. International Journal of Human Resource Management, 9(1), 79-98.

Uradnicek, V. \& Zimkova, E. (2009). Synchronisation of Business Cycles - Cross Country Analyses. 12 $2^{\text {th }}$ International Scientific Conference on Applications of Mathematics and Statitics in Economy (AMSE 2009). Uherske Hradiste, Czech Republic, 439-446.

Waniczek, M. (2002). Berichtsween optimieren: So steigern sie die effizienz in reporting und controlling. $1^{\text {st }}$ ed. München, Germany: Ueberreuter Wirtschaft.

Willcocks, L.P. \& Sykes, R. (2000). Enterprise resource planning: The role of the CIO and it function in ERP. Communications of the ACM, 43(4), 32-38. 